\title{
Sex Differences in Guanfacine Effects on Drug Craving and Stress Arousal in Cocaine-Dependent Individuals
}

\author{
Helen C Fox', Peter T Morgan' and Rajita Sinha*,2 \\ 'Department of Psychiatry, The Connecticut Mental Health Center, Yale University School of Medicine, New Haven, CT, USA; ${ }^{2}$ Department of \\ Psychiatry, The Yale Stress Center, Yale University School of Medicine, New Haven, CT, USA
}

\begin{abstract}
Currently, no FDA-approved medication exists for the treatment of cocaine use disorder. Furthermore, as women become increasingly more at risk for the consequences of cocaine addiction, the need to establish better-tailored treatment medications is paramount. We examine the effects of the alpha2 adrenergic agonist, guanfacine $\mathrm{HCl}$, on responses to stress and drug cue in a group of cocainedependent men and women who also abuse alcohol and nicotine. Forty early abstinent treatment-seeking cocaine-dependent males and females were randomly assigned to receive either daily placebo (I2 M/7 F) or guanfacine (2 or 3 mg) (I 5 M/6 F) for 3 weeks. In week 4 , they participated in a laboratory experiment and were exposed to three 10-min guided imagery conditions (stress/stress, cue/cue, and stress/cue), one per day, consecutively in a random, counterbalanced order. Craving, negative emotion, anxiety, and cardiovascular function were assessed at baseline, immediately following imagery exposure, and at various recovery time points. Guanfacine significantly attenuated cocaine craving, alcohol craving, anxiety, and negative emotion following exposure to all three imagery conditions in females, but not males. Guanfacine did, however, reduce sympathetic tone as well as stress and cue-induced nicotine craving and systolic blood pressure (SBP) in both males and females. These findings highlight sex-specific effects of guanfacine on drug craving, anxiety, and negative mood with significant effects in women and not men. The findings suggest further evaluation of guanfacine in the treatment of cocaine use disorder with a specific focus on sex differences in treatment response.

Neuropsychopharmacology (2014) 39, I527-1537; doi:I0.1038/npp.20 I4. I; published online 5 February 20I4
\end{abstract}

Keywords: guanfacine; stress; drug cue; cocaine use disorder; sex-craving

\section{INTRODUCTION}

Although cocaine use disorder is a serious preventable health-care problem in the United States, no effective FDAapproved medication currently exists. This may be due in part to many tested medications showing high abuse potential and targeting reward (Sofuoglu, 2010; Amato et al, 2011), rather than the attenuation of stress-related craving (Fox and Sinha, in press). Recent societal changes in the demography of cocaine use also means that the traditional gender gap in both licit and street drug consumption has become much smaller (Degenhardt et al, 2008). Furthermore, as extensive risk-related sex differences set women at a disadvantage for compulsive drug use (Becker and $\mathrm{Hu}, 2008$; Fattore et al, 2008) and the negative consequences of drug use in females often appear accelerated or 'telescoped' (Back et al, 2005), the development of an FDA-approved medication that targets this vulnerability

\footnotetext{
*Correspondence: Dr Professor R Sinha, Department of Psychiatry, The Yale Stress Center, Yale University School of Medicine, 2 Church Street South Suite 209, New Haven, CT 065 19, USA, Tel: + I 203737 5805, Fax: + 203974 7076, E-mail: rajita.sinha@yale.edu

Received 23 August 2013; revised 8 November 2013; accepted II November 2013; accepted article preview online 7 January 2014
}

in women is imperative. As cocaine-dependent individuals commonly co-abuse alcohol and nicotine (Carroll et al, 1993; McCance-Katz et al, 1998; Carroll et al, 2000; Patkar et al, 2006), medications targeting stress systems that mediate craving for multiple drugs of abuse is also important. We therefore propose to investigate guanfacine $\mathrm{HCl}$, a non-stimulant agent, with minimal side effects, that targets stress-provoked craving for multiple drugs and that may be particularly efficacious in women with cocaine use disorder.

As an alpha2 adrenergic agonist, guanfacine stimulates presynaptic alpha $2 \mathrm{~A}$ receptors located on noradrenergic neurons throughout the mesocorticolimbic pathways (Uhlen et al, 1994; Scahill et al, 1999). This induces central inhibition of norepinephrine (NE) via the attenuation of $\mathrm{NE}$ release from terminals and firing from cell bodies in the locus coeruleus (Engberg and Eriksson, 1991). Guanfacine also promotes a downregulation of sympathomimetic outflow from the vasomotor center of the brain to the heart (Sica, 2007). Notably, extensive preclinical and clinical research has shown that both of these central and peripheral mechanisms may have a salient role in the reduction of cocaine craving, owing to the fact that activation of the lateral tegmental NE system (Shaham et al, 2000; Erb, 2010; Sinha et al, 2011; Mantsch et al, 2013) and autonomic 
peripheral arousal (Sinha et al, 2003; Fox et al, 2008b, 2009) are implicated in stress-induced motivation for, and relapse to, cocaine during early recovery.

For example, evidence shows that the discontinuation of cocaine has been associated with adrenergic dysregulation within neural systems associated with the control of rewarding and aversive motivational states. These adaptations include the desensitization of alpha2-adrenoceptors in the mediobasal hypothalamus (Baumann et al, 2004), increased activation of corticotrophin releasing hormone and NE in the central nucleus of the amygdala (CeA) and BNST (Shalev et al, 2002; Shaham et al, 2003), and heightened NE responsivity to stress in humans (Fox et al, 2005). Most notably, these withdrawal-related alterations have been shown to underpin stress-induced reinstatement of cocaine in rats (Shaham et al, 2000; Sinha et al, 2011), as well as the negative reinforcing effects of cocaine such as depressive-like symptoms (Siever and Uhde, 1984) and elevated anxiety and panic attacks (McDougle et al, 1994; Smith and Aston-Jones, 2008). As enhanced negative affect and sympathetic sensitivity to stress and drug cues during early withdrawal have been associated with elevated craving and relapse vulnerability (Sinha et al, 2003; Fox et al, 2005, 2008b, 2009), centrally mediated inhibition of NE, via functional antagonism of noradrenergic signaling, may provide a salient mechanism for medications development.

In support, preclinical studies indicate that guanfacine and other alpha 2 adrenergic agonists such as clonidine and lofexidine are able to block stress-induced reinstatement to cocaine self-administration (Erb et al, 1998; Erb et al, 2000). Clonidine has also prevented forced swim-induced reinstatement in mice (Mantsch et al, 2010). Similarly, in humans, lofexidine has been shown to decrease stress- and drug cue-related opiate craving in opiate dependent individuals also treated with naltrexone (Sinha et al, 2007b). Moreover, in a recent preliminary study, we showed that guanfacine decreased cue-related cocaine craving, anxiety, and arousal in individuals with cocaine dependence (Fox et al, 2012).

Although guanfacine may be a promising medication for cocaine addiction because of its mediation of sympathetic function, these stress pathways are inextricably meshed with gonadal systems, and hence are highly sex specific (Fox and Sinha, 2009). Studies show robust sex variation in the stress- and cue-induced craving state (Brady et al, 2006; Saladin et al, 2012) with women generally reporting significantly higher ratings of anxiety, stress, and negative affect (Back et al, 2005; Chaplin et al, 2008; Fox et al, 2008b; Fox and Sinha, 2009) alongside unique sympathetic dysregulation patterns compared with those of men (Fox et al, 2006; Fox et al, 2009). Preclinical studies have also shown sex diversity with female rats displaying longer HPA-axis activation and greater NE response to stressors compared with male rats (Heinsbroek et al, 1990; Heinsbroek et al, 1991).

We therefore assessed the effects of guanfacine on craving, anxiety, and negative mood during exposure to stress and drug cues in men $v s$ women with cocaine dependence who also abused alcohol and nicotine. We hypothesized that the effects of guanfacine would be sex specific, with women potentially showing enhanced benefit from adrenergic medication compared with males. To test this hypothesis, we conducted a double-blind, placebocontrolled laboratory study designed to determine subjective and cardiovascular response to stress- and cue-related imagery in a group of cocaine-addicted men and women after 3 weeks of treatment with guanfacine (up to $3 \mathrm{mg} /$ day) vs placebo.

\section{MATERIALS AND METHODS}

\section{Participants}

Forty treatment-seeking individuals with cocaine dependence $(13 \mathrm{~F} / 27 \mathrm{M})$ were recruited from the local area using newspaper and on-line advertisements. The Structured Clinical Interview for the Diagnostic and Statistical Manual of Mental Disorders IV (First et al, 1995) and positive urine toxicology screens were used to determine current cocaine dependence. Exclusion criteria included DSM-IV dependence for any drug other than cocaine, alcohol, or nicotine. Participants using prescribed medications for any psychiatric or medical disorders were also excluded, and all individuals underwent stringent medical assessments including electrocardiography and laboratory tests of renal, hepatic, pancreatic, hematopoietic, and thyroid function. Written and verbal consent were obtained from all participants, and procedures were approved by the Human Investigation Committee of the Yale University School of Medicine.

\section{General Procedures}

The study comprised three laboratory sessions conducted during inpatient stay, and 3-4 weeks following admission to the Clinical Neuroscience Research Unit of the Connecticut Mental Health Center (CMHC). During these sessions, three personalized guided imagery scripts were presented to participants, one per day, across 3 consecutive days in a randomized and counterbalanced order. The imagery conditions were: (i) stress, (ii) cue, and (iii) combined stress and cue. All imagery conditions were 10 min long.

The Clinical Neuroscience Research Unit is a locked inpatient treatment research facility with no access to alcohol or drugs and very limited access to visitors. Drug testing was conducted regularly to ensure drug abstinence. As subjects were all treatment seeking, they participated in standard and individual group counseling treatment for cocaine addiction while on the unit.

\section{Guanfacine Dosing Schedule}

All guanfacine pills were marketed by Watson Pharmaceuticals and purchased through the pharmacy located at the CMHC. The research pharmacist ensured that both active and placebo (lactose) capsules used for medication administration appeared identical. All subjects were randomly assigned to either guanfacine ( 2 or $3 \mathrm{mg}$ ) or placebo. On day 5 of inpatient admission, participants were initiated on a 12-day titration schedule, similar to that used in previous human studies (Scahill et al, 2001; Biederman et al, 2008), with morning doses administered at 08:00 AM and evening doses at 08:00 PM. Briefly, participants who randomized 
to the dose of guanfacine $2 \mathrm{mg}$ started dosing on days 1-3 (0.5 mg evening), on days $4-13$ ( $0.5 \mathrm{mg}$ morning and $1.0 \mathrm{mg}$ evening), and weeks 2 onwards (1.0 mg morning and $1.0 \mathrm{mg}$ evening). Participants who randomized to the dose of guanfacine $3 \mathrm{mg}$ started dosing on days $1-2(0.5 \mathrm{mg}$ evening), on days 3-5 (0.5 mg morning and $1.0 \mathrm{mg}$ evening), on days $6-8$ (1.0 mg morning and $1.0 \mathrm{mg}$ evening), on days 9-11 (1.0 mg morning and $1.5 \mathrm{mg}$ evening), and on day 12 onwards (1.5 mg morning and $1.5 \mathrm{mg}$ evening). All laboratory sessions were conducted in week $4, \sim 21$ days after admission. Following the laboratory sessions, and on completion of inpatient stay (5 weeks), all participants underwent a standard 5-day taper (Strang et al, 1999). Urn randomization procedures to match groups on age, sex, and education variables were conducted by the CMHC research pharmacist (Stout et al, 1994).

\section{Imagery Script Development Procedures}

These are presented in full in the studies by Bergquist et al, (2010) and by Sinha (2009). Briefly, the stress scripts were based on subjects' descriptions of recent personal stressful events described as being 'most stressful' on a 10-point Likert scale. Only scripts scored 8 or above and containing no drug-related scenarios were accepted for later use in the laboratory challenge studies. The drug cue scripts were developed by having subjects to identify recent situations that included drug-related stimuli, resulted in subsequent cocaine use, and included no stressful scenarios. The stress and drug cue combined script-elicited situations where a stressful scenario was followed by a drug-related event. Once the situations were elicited, 10-min scripts (comprising two combined, 5-min scripts) were developed for the three laboratory sessions: stress/stress, cue/cue, and stress/ cue. Each imagery script was then audio-taped and presented as part of the laboratory challenge procedures.

\section{Laboratory Challenge Procedures (Conducted Across 3 Consecutive Days)}

On each of the 3 testing days, all subjects were abstained from breakfast and were allowed an initial smoke break at 07:30 AM in order to reduce craving. They were then brought into the testing room at 07:45 AM. Self-reports of craving, anxiety, and mood were completed immediately after setup at 08:00 AM. This was followed by a 45-min adaptation period during which the subjects were instructed to practice relaxation. Following the collection of baseline measures, at 09:10 AM, subjects were provided headphones and given the following instructions for the imagery procedure: 'Close your eyes and imagine the situation being described, 'as if it were happening right now. Let your body and mind get completely involved in the situation, doing what you would do in the real situation'. Pulse and blood pressure were continuously monitored during imagery presentation. Subjective and cardiovascular measures were obtained at baseline (B), immediately following imagery (0 time point), $5 \mathrm{~min}$ after ( +5 time point) and then periodically every $15 \mathrm{~min}$ after up to $65 \mathrm{~min}$ post imagery $(+20,+35,+50,+65$ time points). At the end of each session, relaxation instructions were provided.
Collection times for all subjective and cardiovascular measures are presented in Supplementary Information S1.

\section{Laboratory Assessments}

Four separate visual analog scales, anchored from 1 (not at all) to 10 (extremely high), were used for measuring cocaine craving, alcohol craving, nicotine craving, and anxiety. The Differential Emotion Scale (Izard, 1972) was used to rate negative emotion. The scale comprises 30 adjectives (or items) and participants were required to rate on a 5-point scale the extent to which each word describes the way she/he felt at the current time. Negative emotion ratings included a composite score of 'sadness' and 'anger' sub-scales. A Critikon Dinamap 120 Patient Monitor (Soma Technology, CT) was used to assess blood pressure and pulse rate.

\section{Statistical Analyses}

Linear mixed effect models were implemented to analyze the data, using SPSS software (version 19). Within-subjects factors of imagery condition (stress/stress, cue/cue, and stress/cue), time point (varying levels), and Betweensubjects factors of medication group (guanfacine (2 and $3 \mathrm{mg}$ collapsed) $v s$ placebo) and sex (males $v s$ females) were the fixed effects. Subjects represented the random effects. Baseline data were used as covariates in all analyses in order to account for variability across each testing day. A first order autoregressive covariance structure was applied to all linear mixed effect models. $T$-tests and $\chi^{2}$-tests were used to compare groups on demographic and drug use variables.

In the primary analysis, the guanfacine group comprised two doses: 2 and $3 \mathrm{mg}$ collapsed. Doses were collapsed owing to small sample size and no previous evidence of dose effects for 2 and $3 \mathrm{mg} /$ day doses. However, we conducted secondary analysis examining guanfacine dose on tonic and phasic stress system adaptations, in which medication dose (placebo vs $2 \mathrm{mg}$ guanfacine $v s 3 \mathrm{mg}$ guanfacine) represented a between-subject fixed effect. Owing to small numbers of females in the dose categories, these extended dose findings are preliminary only.

\section{RESULTS}

\section{Participants}

Table 1 presents demographics and baseline differences in key outcome variables. Both guanfacine and placebo males and females were statistically well matched in terms of demographic and drug use variables, with the exception that females had consumed a greater quantity of cocaine in the month preceding inpatient admission compared with males. They also had significantly higher BMIs compared with the males. As elevated BMI and cocaine use in the females might potentially act as a confounding variable for sex differences, secondary analyses were performed using BMI and amount of cocaine before inpatient treatment as a covariates. These additional covariates had no significant effect on any of the linear mixed effect models. The reported findings below therefore document baseline only as a covariate. Raw values (means and SDs) for all subjective measures are presented in Supplementary Informations S2 and S3. 
Table I Demographic and Drug Use

\begin{tabular}{|c|c|c|c|c|}
\hline \multirow[t]{2}{*}{$\mathbf{N}=\mathbf{4 0}$} & \multicolumn{2}{|c|}{ Placebo $(n=19)$} & \multicolumn{2}{|c|}{ Guanfacine $(n=21)$} \\
\hline & Females, $n=7$ & Males, $n=12$ & Females, $n=6$ & Males, $n=15$ \\
\hline \multicolumn{5}{|l|}{ Race } \\
\hline Hispanic & $2(28.6 \%)$ & | (8.3\%) & $0(0)$ & $2(13.3 \%)$ \\
\hline Years spent in education ${ }^{\mathrm{a}}$ & $11.6 \pm 1.8$ & $12.7 \pm 2.7$ & $11.8 \pm 0.4$ & $11.8 \pm 1.7$ \\
\hline No. of regular smokers & $7(100 \%)$ & II (92\%) & $5(83 \%)$ & $13(87 \%)$ \\
\hline BMI & $29.3 \pm 7.1$ & $26.7 \pm 4.7$ & $32.0 \pm 5.3$ & $24.4 \pm 4.3$ \\
\hline Years of alcohol use $\mathrm{a}^{\mathrm{a}}$ & $13.0 \pm 9.9$ & $18.6 \pm 8.2$ & $19.8 \pm \mid 1.1$ & $13.6 \pm 10.4$ \\
\hline No. of days used in past month ${ }^{\mathrm{a}}$ & $16.3 \pm 12.6$ & $13.7 \pm 9.3$ & $16.0 \pm 10.9$ & $13.6 \pm 12.3$ \\
\hline Amount of alcohol use in past month ${ }^{\mathrm{a}}$, (drinks) & $181.0 \pm 203.3$ & $266.6 \pm 331.8$ & $218.2 \pm 244.6$ & $287.8 \pm 431.5$ \\
\hline Lifetime alcohol dependence & $3(42.9 \%)$ & $8(66.7 \%)$ & $4(66.7 \%)$ & $6(40 \%)$ \\
\hline Lifetime mood & $3(42.9 \%)$ & | (8.3\%) & $0(0)$ & $2(13.3 \%)$ \\
\hline Lifetime anxiety (including PTSD) & $4(57.1 \%)$ & $2(16.7 \%)$ & I (I6.7\%) & $6(40 \%)$ \\
\hline Lifetime anxiety (without PTSD) & $0(0)$ & $2(16.7 \%)$ & $0(0)$ & $0(0)$ \\
\hline
\end{tabular}

${ }^{a}$ Data indicate means and SD. Bold area: $p<0.05$.

\section{Safety and Tolerability}

Consistent with our initial laboratory project assessing the effects of guanfacine on stress- and cue-induced cocaine craving (Fox et al, 2012), the current dosing schedule was shown to be safe and well tolerated in both males and females. Side effects were reported in $46.7 \%$ of guanfacine males, $66.7 \%$ of guanfacine females, $85.7 \%$ of placebo females, and $33.3 \%$ of placebo males. All side effects were reported as being mild to moderate and dissipated within the initial 2 weeks of inpatient stay. Only three participants administered guanfacine continued to report mild symptoms into the third week ( 1 female/2 male). The list of common side effects is presented in Supplementary Information S4.

\section{Baseline Findings}

Cardiovascular measures. A significant main effect of medication group $(\mathrm{F}(1,37)=35.5, p<0.0001)$ and sex $(\mathrm{F}(1,37)=4.8, p<0.04)$ showed that basal heart rate was significantly higher in females compared with males and significantly lower in participants administered guanfacine compared with placebo. A significant medication group $\times$ sex interaction $(\mathrm{F}(1,37)=8.9, \quad p=0.005)$ also showed that while guanfacine significantly lowered basal heart rate compared with placebo in both males $(p=0.001)$ and females $(p<0.0001)$, heart rate was reduced to a greater extent in females. This was owing to the fact that basal beats per minute were significantly higher in placebo females compared with placebo males $(p=0.01)$ (Figure 1a).

Guanfacine significantly reduced basal systolic blood pressure (SBP) $(\mathrm{F}(1,37)=5.0, p=0.03)$ and diastolic blood pressure (DBP) $(1,38=6.1, p<0.02)$ compared with placebo in both males and females (Figure $1 \mathrm{~b}$ and $\mathrm{c}$ ). A main effect of sex for both SBP $(1,37=6.1, p<0.02)$ and DBP $(1,38=5.9, p=0.02)$ also indicated, as expected, that males had higher tonic blood pressure compared with females. A significant medication group $\times$ sex interaction for $\operatorname{DBP}(1,38=4.4, p=0.04)$ additionally indicated that basal DBP was reduced in guanfacine males compared with placebo males $(p<0.0001)$. This attenuation of blood pressure in males may have been owing to the fact that basal DBP was significantly elevated in placebo males compared with placebo females $(p=0.003)$.

No effects of dose were observed between the 2 and $3 \mathrm{mg}$ guanfacine groups with regard to basal cardiovascular output.

\section{Response Findings}

Highest order interaction terms and main effects only are presented in the text. All lower order interactions and main effects are presented in Table 2.

\section{Subjective Craving Measures (Baseline Adjusted)}

Cocaine craving. A significant medication group $\times \operatorname{sex} \times$ time-point interaction was observed $(\mathrm{F}(5,501)=5.1$, $p<0.0001$ ), where guanfacine females reported significantly 

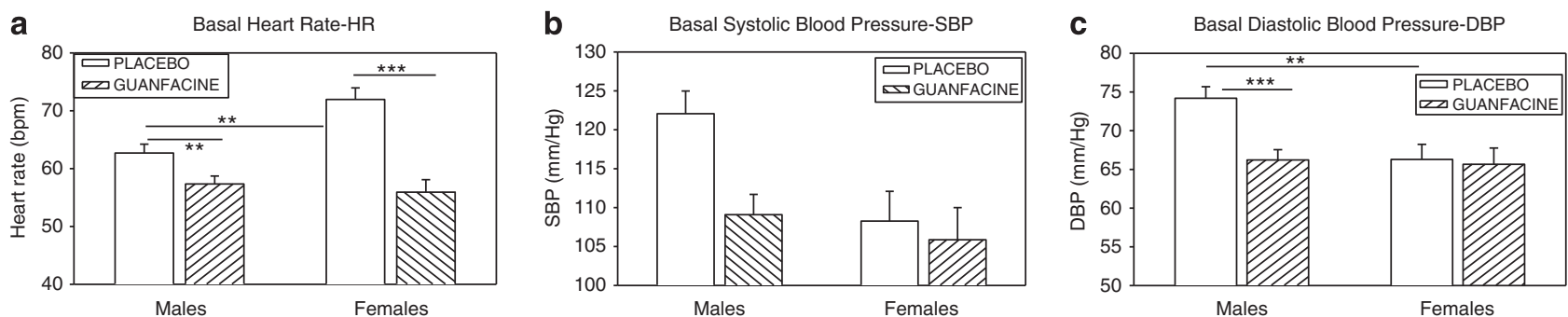

Figure I (a) Basal heart rate. Bar graph shows a medication group $\times$ sex interaction (GUAN F $<P L A F, p<0.000$ I; GUAN M $<$ PLA M, $p=0.00$ I; PLA F $>$ PLA $M, p=0.01$ ). A main effect of medication group (GUAN $<$ PLA, $p<0.000 I$ ) and sex $(F>M, p<0.04)$ were also observed. (b) Basal systolic blood pressure (SBP). Bar graph shows a main effect of medication group (GUAN $<$ PLA, $p=0.03$ ) and sex (M>F, $p<0.02$ ). (c) Basal diastolic blood pressure (DBP). Bar graph shows a medication group $\times$ sex interaction (GUAN $M<P L A M, p<0.000 I ; P L A \quad M>P L A F, p=0.003$ ). A main effect of medication group (GUAN $<$ PLA, $p<0.02)$ and $\operatorname{sex}(M>F, p=0.02)$ were also observed. $* * * * 00.000 I$; *** $p \leqslant 0.01$. $F$, females; GUAN, guanfacine; M, males; PLA, placebo.

Table 2 Lower Order Interaction and Main Effects not Displayed in the Text

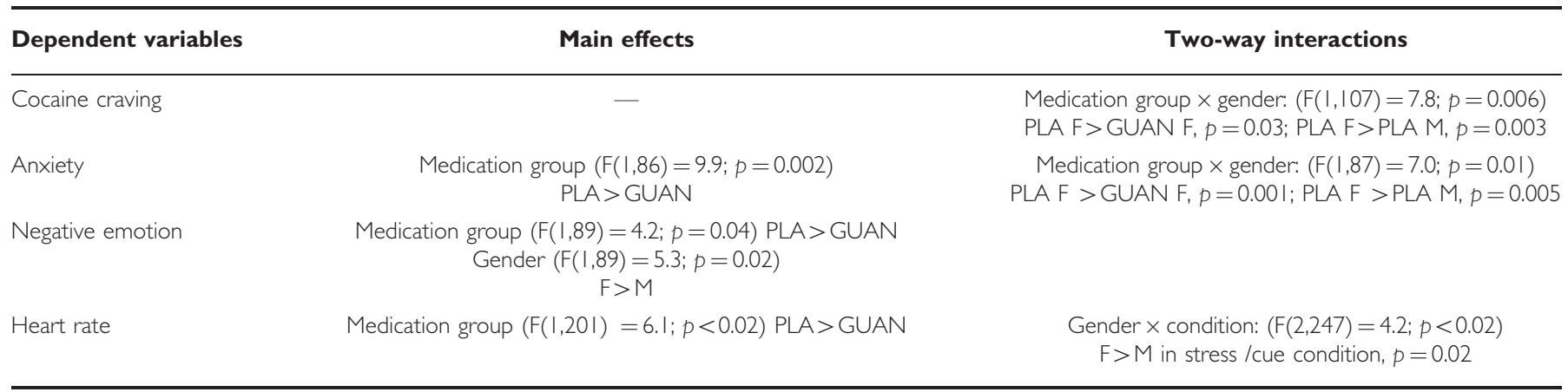

Abbreviations: F, females; GUAN, guanfacine; M, males; PLA, placebo.

All higher order main effects and interactions displayed in the text.

lower levels of cocaine craving compared with placebo females immediately following imagery presentation ( 0 time point: $p<0.0001)$ and 5 min later $(+5$ time point: $p<0.02)$ (Figure 2a). This reduction in cocaine craving in the guanfacine females may have been instigated by the high levels of cocaine craving observed in the female placebo group compared with the male placebos immediately following the presentation of all three imagery conditions ( 0 time point: $p<0.0001)$ and $5 \mathrm{~min}$ later $(+5$ time point: $p<0.0001$ ). Conversely, in the males, the guanfacine group reported significantly higher ratings of cocaine craving than the placebo males immediately following imagery exposure $(p<0.0001)$.

The attenuation of cocaine craving in guanfacine females and increase in cocaine craving in the guanfacine males compared with placebos was observed across all three imagery conditions, as no significant imagery condition interactions were observed between sex (sex $\times$ imagery, $p=0.71$ ) and medication group (medication group $\times$ imagery, $p=0.80$ ).

Alcohol craving. A significant medication group $\times$ sex $\times$ time point interaction was observed $(\mathrm{F}(5,492)=3.4$, $p=0.005$ ), where guanfacine females reported significantly lower levels of alcohol craving compared with placebo females immediately following imagery presentation (0 time point: $p<0.0001)$ and $5 \mathrm{~min}$ later $(+5$ time point: $p=0.003$ ) (Figure $2 \mathrm{~b}$ ). Again, the reduced alcohol craving seen in the females guanfacine group may have been related to the high ratings of craving reported by the female placebo group comparative to the male placebos immediately following exposure to all three imagery conditions $(p=0.001)$. This attenuation in alcohol craving was not observed in the male guanfacine group and was reported in guanfacine females across all three imagery conditions, as no significant imagery condition interactions were observed between sex (sex $\times$ imagery, $p=0.67)$ and medication group (medication group $\times$ imagery, $p=0.53$ ).

Nicotine craving. A significant main effect of medication group was observed $(\mathrm{F}(1,37)=9.9, p=0.003)$, showing that guanfacine reduced nicotine craving in both male and female cocaine-addicted individuals, following exposure to all three imagery conditions and across all time-points (Figure 2c). No significant interactions were observed between medication group, sex, imagery condition, and time points.

\section{Subjective Anxiety and Mood Measures (Baseline Adjusted)}

Anxiety. A significant medication group $\times \operatorname{sex} \times$ timepoint interaction was observed $(\mathrm{F}(5,520)=7.0, p<0.0001)$, where guanfacine females reported significantly lower levels of anxiety compared with placebo females immediately 
a
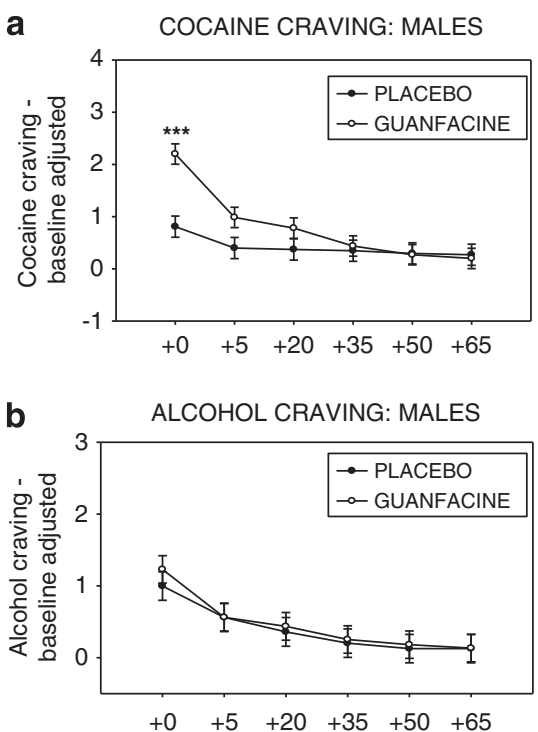

C NICOTINE CRAVING: MALES

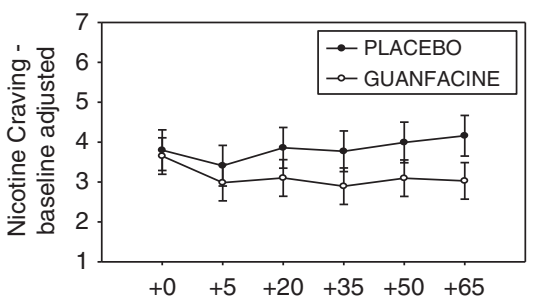

COCAINE CRAVING: FEMALES

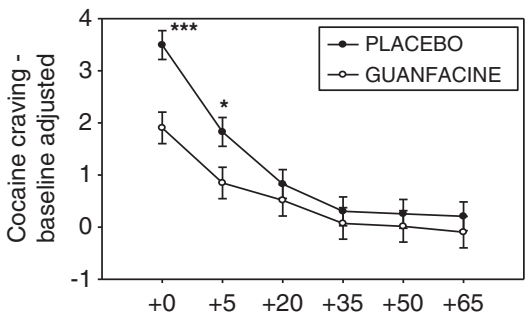

ALCOHOL CRAVING: FEMALES

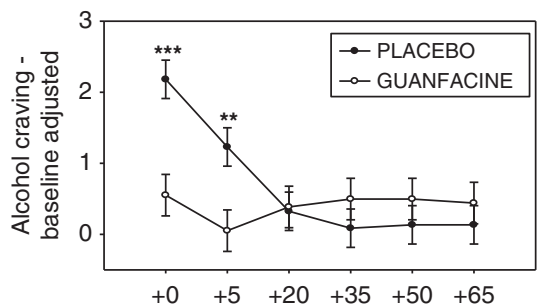

NICOTINE CRAVING: FEMALES

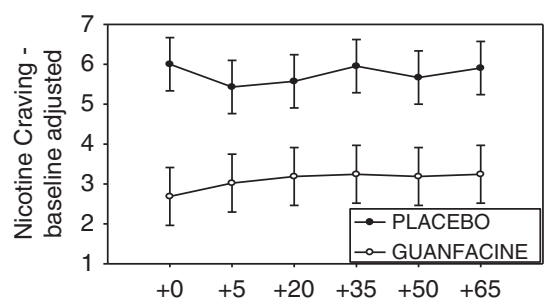

Figure 2 (a) Cocaine craving. Line graphs show a medication group $\times$ sex $\times$ time-point interaction (GUAN F $<$ PLA F at $0, p<0.000$ I and +5 time points, $p<0.02$; PLA F $>$ PLA M at 0 and +5 time points; GAUN M $>$ PLA M at 0 time point, $p<0.000$ I in all cases). (b) Alcohol craving. Line graphs show a medication group $\times$ sex $\times$ time-point interaction (GUAN F $<$ PLA F at 0 time point, $p<0.000$ I and +5 time point, $p=0.003$; PLA F $>$ PLA M at 0 time point, $p=0.00 \mathrm{I}$. (c) Nicotine craving. Line graphs show a main effect of medication group (GUAN $<$ PLA, $p=0.003$ ). Data in all graphs are collapsed across all three imagery conditions, as no significant condition interactions were observed. All graphical data are adjusted for baseline and represent means and SE. ***** $p<0.000$ I; ** $p \leqslant 0.0$ I; * $p \leqslant 0.05$. F, females; GUAN, guanfacine; M, males; PLA, placebo.

a

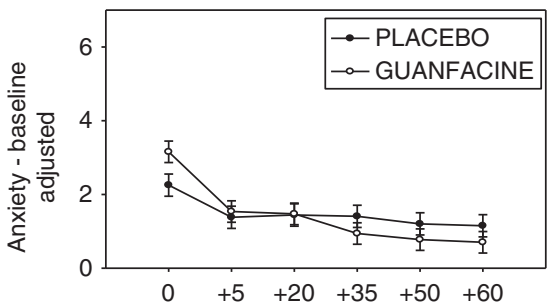

b

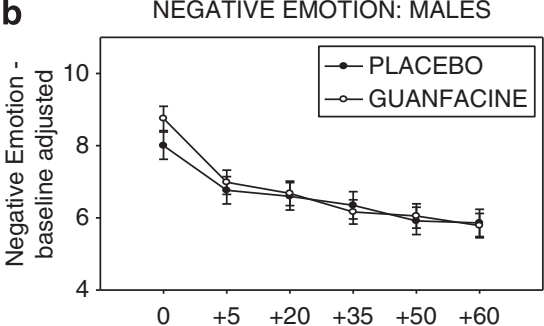

ANXIETY: FEMALES

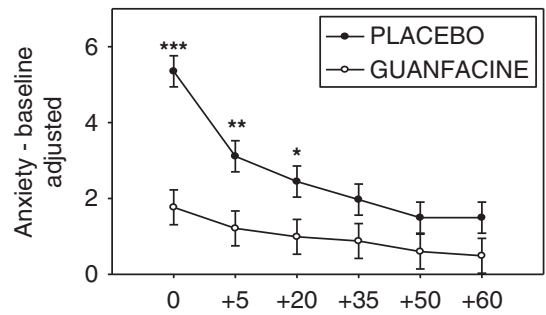

NEGATIVE EMOTION: FEMALES

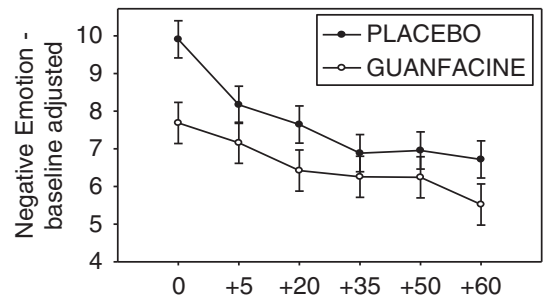

Figure 3 (a) Anxiety. Line graphs show a medication group $\times$ sex $\times$ time-point interaction (GUAN F $<$ PLA F at 0 time point, $p<0.000$ I, +5 time point, $p=0.002$ and +20 time point, $p<0.02$; PLA F $>$ PLA M at $0, p<0.000 \mathrm{I}$ and +5 time points, $p=0.00 \mathrm{I}$ ). (b) Negative emotion. Line graphs show a medication group $\times$ sex interaction (GAUN F $<$ PLA F, $p<0.04$; PLAF $>$ PLAM, $p<0.02$ ). Data in all graphs are collapsed across all three imagery conditions as no significant condition interactions were observed. All graphical data are adjusted for baseline and represent means and SE. **** $p<0.000$ I; *** $\leqslant 0.0$ I; * $p \leqslant 0.05$. F, females; GUAN, guanfacine; M, males; PLA, placebo. 
following imagery presentation (0 time point: $p<0.0001$ ), 5 min later ( +5 time point: $p=0.002$ ), and 15 min later $(+20$ time point: $p<0.02$ ) (Figure 3a). Again, reduced anxiety levels seen in the guanfacine females may have been the result of high anxiety ratings reported by the female placebo group compared with the male placebo group immediately following exposure to all three imagery conditions $(p<0.0001)$ and $5 \mathrm{~min}$ later $(p=0.001)$. This attenuation in anxiety was not seen in the guanfacine males and was observed across all three imagery conditions, as no significant imagery condition interactions were observed between sex $(\operatorname{sex} \times$ imagery, $p=0.72)$ and medication group (medication group $\times$ imagery, $p=0.24$ ).

Negative emotion (composite score of anger and sadness). A significant Medication Group X Sex interaction was observed $(\mathrm{F}(1,84)=4.0, p<0.05)$ showing that again females who were administered guanfacine reported a significant attenuation in negative emotion compared with females given placebo across all imagery conditions and time-points $(p<0.04)$ (Figure 3b). Elevated levels of negative emotion were also reported by the female placebos compared with the male placebo group $(p<0.02)$.

\section{Cardiovascular Measures (Baseline Adjusted)}

A significant medication group $\times \operatorname{sex} \times$ imagery condition interaction for heart rate $(\mathrm{F}(2,246)=4.2, p>0.02)$ showed that beats per minute were reduced across all time points in the guanfacine females compared with the placebo females in the stress/cue imagery condition only $(p<0.0001)$. Again, the guanfacine-related attenuation in heart rate in the females may have been related to the elevated heart rate observed in the placebo females compared with the placebo males across all time points in the stress/cue imagery condition $(p<0.0001)$. No differences between the male placebo groups $v s$ the male guanfacine groups were observed.

A main effect of sex was observed for both SBP $(\mathrm{F}(1,113)=8.8, \quad p=0.004) \quad$ and $\mathrm{DBP} \quad(\mathrm{F}(1,146)=6.0$, $p<0.02)$, showing that, as expected, females demonstrated lower blood pressure compared with males. An additional main effect of medication group for $\operatorname{SBP}(\mathrm{F}(1,113)=10.2$, $p=0.002)$ showed that participants who received guanfacine demonstrated significantly lower SBP compared with those who received placebo following all imagery conditions.

\section{Effect Sizes}

Effect sizes ranged from moderate $(f=0.32$ negative emotion; $f=0.46$ heart rate; $f=0.50$ nicotine craving; and $f=0.65$ alcohol craving) to high $(f=0.80$ cocaine craving and $f=0.94$, anxiety).

\section{Secondary Analysis (Dose)}

Dose analysis showed significant dose $\times$ sex $\times$ time-point effects for cocaine craving $(\mathrm{F}(10,472)=3.1, p=0.001)$ and alcohol craving $(\mathrm{F}(10,463)=2.1, p=0.02)$. In both cases, the attenuation of craving in the guanfacine females was reduced more robustly by the higher $3 \mathrm{mg} /$ day guanfacine dose relative to placebo, and no differences were seen in the
$2 \mathrm{mg} /$ day $v s$ placebo. Immediately following exposure to all three imagery conditions (0 time point), the females on $3 \mathrm{mg} /$ day of guanfacine reported significantly lower cocaine craving compared with the placebo group $(p<0.0001)$. Five minutes later $(+5$ time point), they reported lower cocaine craving ratings compared with both the placebo group $(p=0.003)$ and the females who had been administered $2 \mathrm{mg}$ of guanfacine $(p=0.05)$. This effect of dose was not observed in the males. With regard to alcohol craving, immediately after exposure to all three imagery conditions, the female placebo group reported significantly higher alcohol craving compared with the women that had been administered both $2 \mathrm{mg}$ of guanfacine $(p<0.0001)$ and $3 \mathrm{mg}$ of guanfacine $(p<0.03)$. However, 5 min later $(+5$ time point), only the higher $3 \mathrm{mg}$ dose of guanfacine was reducing alcohol craving compared with placebo $(p=0.04)$. Graphs for the extended dose analyses are presented in Supplementary Information S5.

No significant variation between 2 and $3 \mathrm{mg} /$ day of guanfacine were observed with regard to any other subjective or cardiovascular measures.

\section{DISCUSSION}

Current findings indicated that 3 weeks of guanfacine treatment culminated in phasic attenuation of cocaine and alcohol craving, as well as anxiety and negative emotion following stress and cue in females, but not males. However, nicotine craving was reduced in both guanfacine males and females. Guanfacine also attenuated cardiovascular output in both males and females, although basal heart rate was reduced more robustly in females and basal DBP was reduced more robustly in males. Basal and phasic SBP was reduced across-the-board in both guanfacine males and females. Although guanfacine decreased generalized cardiovascular output in both males and females, current findings indicate that the attenuation of craving and emotion was far more robust in females. Preliminary dose analysis further indicated that the higher dose of $3 \mathrm{mg} /$ day was significantly more effective in attenuating stress- and cue-related cocaine and alcohol craving than the $2 \mathrm{mg}$ /day dose. Consistent with prior research (Fox et al, 2012), both doses were found to be well tolerated in the current participant sample.

The significant reduction observed in craving, anxiety, and negative emotion in the guanfacine female group may have stemmed predominantly from the significantly higher ratings reported in all measures by the placebo females compared with both the guanfacine females and the placebo males. This is consistent with extensive research showing that both cocaine-dependent and non-dependent females report significantly higher anxiety, stress, and negative mood during distress compared with males, (Chaplin et al, 2008; Fox et al, 2008b) and experience negative emotions at a greater frequency and intensity than males (Nolen-Hoeksema et al, 1999). Findings also support clinical data, indicating that US women are markedly overrepresented with regard to stress-related psychopathology including anxiety and mood disorders (Blanchard, 1998; McCance-Katz et al, 1999). In view of this, potentiated stress- and cue-related negative mood and anxiety might represent a salient motivational component of the provoked 
craving state in dependent women (Chaplin et al, 2008; Fox et al, 2009; Fox and Sinha, 2009). As an adrenergic agonist, guanfacine targets core anxiety-related corticotrophin releasing hormone and NE sympathetic pathways (Arnsten, 2011); and this mechanism may therefore underlie its efficacy in reducing anxiety, negative emotion, and thus craving for multiple drugs of abuse in dependent females.

It is important to note that guanfacine did significantly attenuate nicotine craving across sex, and this may reflect the increased ratings of nicotine craving in the placebo groups relative to alcohol and cocaine craving. This again corroborates prior research from our laboratory that has incorporated similar paradigms, and documented comparatively elevated nicotine craving, possibly owing to consumption expectations (Fox et al, 2012). Although participants were resident in a locked inpatient unit with no access to either cocaine or alcohol, they were allowed four supervised smoking breaks per day and additional cigarette breaks before and following each of the three laboratory challenge studies. Higher consumption expectancy for nicotine may therefore have increased craving levels in both males and females optimizing guanfacine's efficacy in reducing nicotine craving. Craving may therefore need to be above a particular threshold for guanfacine to be effective in reducing craving, and this may further account for guanfacine's greater efficacy in attenuating stress- and cue-induced cocaine and alcohol craving in females compared with males. In both cases, placebo females reported significantly greater ratings of craving compared with placebo males.

Although guanfacine was efficacious in attenuating both stress- and cue-induced cocaine craving in women, it actively potentiated cocaine craving immediately following exposure to all three imageries in men. From a broad perspective, this may be related to a number of sex differences in the pharmacodynamic and pharmacokinetic mechanisms mediating cocaine craving in men. In support of this, animal studies have shown that under certain conditions, and in certain individuals, alpha2 agonists may act like NE and selectively agonize other receptors. For example, at higher doses, the alpha2 agonist, clonidine has been shown to saturate presynaptic alpha2 receptors and activate lower affinity post-synaptic receptors, as well as bind to imidazoline I(1) receptor sites (Eglen et al, 1998). This serves to mimic the counterintuitive 'stimulant-like' effects of NE potentially increasing the motivation for cocaine (Feltenstein and See, 2006; Brown et al, 2009).

Furthermore, while low doses of clonidine have successfully blocked both forced swim- and yohimbine-induced cocaine reinstatement in male mice, higher doses have not only failed to block reinstatement under comparative conditions, but actively induced cocaine reinstatement (Mantsch et al, 2010) and conditioned place preference (Cervo et al, 1993). With regard to the current findings, therefore, this poses questions concerning possible sex differences in pharmacokinetic and pharmacodynamic processes relating to the bioavailability of guanfacine, alpha2-receptor binding, and cocaine craving. Moreover, as nicotine craving was attenuated in the present study in both guanfacine males and females, findings also indicate the possibility of selective mechanisms underlying craving for different drugs of abuse.
These sex-specific variations observed in the current study may also help account for the less robust attenuation of stress-induced cocaine craving and negative mood observed previously in a combined sample of males and females with cocaine dependence using an identical paradigm (Fox et al, 2012). In our previous study, guanfacine just reduced cue-related cocaine craving, and showed only a trend in terms of attenuating stress- and cue-induced negative mood. It is therefore possible that potential experimental findings may have been 'washed out' by combining gender. Similarly, our previous research indicated that guanfacine reduced stress- and cue-related nicotine craving more robustly than cocaine craving, perhaps owing to less sex specificity.

In terms of cardiovascular output, tonic heart rate and blood pressure were reduced in both male and female guanfacine groups compared with placebos. Heart rate was more robustly reduced in the guanfacine females because of significantly higher beats per minute in women as documented in the female compared with male placebos. Similarly, DBP was more strongly attenuated in the guanfacine males also possibly because of higher blood pressure levels in the male compared with the female placebos. The sex dissociations in heart rate and blood pressure observed in the placebo groups support research documenting the prevalence of raised resting and provoked heart rate in healthy (Burke et al, 1996; Ostadal and Ostadal, 2012) and cocaine-dependent females (Fox et al, 2006; Brady et al, 2009), and elevated tonic and phasic blood pressure in healthy (Sandberg and Ji, 2012) and cocainedependent males (Kudielka et al, 2004; Fox et al, 2006). Similar to the subjective data, therefore, findings suggest that a particular threshold of emotional and sympathetic arousal may be required to optimize guanfacine efficacy.

The upregulation in cardiac activity documented in the current placebo groups was not within a risk-related range. However, increased autonomic, and cardiovascular tone, even at non-clinical levels, have still been associated with risk-related behaviors. These include persistent elevations in cocaine craving, alcohol craving, anxiety, and dysregulated phasic heart rate and blood pressure response to stress (Kampman et al, 2006; Fox et al, 2008b; Sinha et al, 2009). As such, upregulated heart rate more commonly observed in females (Ostadal and Ostadal, 2012) may provide another salient target for the therapeutic effects of guanfacine in women, highlighting a mechanism that may be associated with the attenuation of anxiety, arousal, negative emotion, and thus craving, in stressful and vulnerable environments. Conversely, in males, guanfacine-induced attenuation of both basal and response blood pressure was not accompanied by a corresponding decrease in either stress- and cue-related craving or negative emotion.

This again points to sex specificity in the processes underlying the stress-induced craving state, and may support several studies that have shown cardiovascular and sympathetic arousal to be associated with anxiety symptomatology to a greater extent in females compared with males (Cahill, 2003). As such, the autonomic and physiological correspondence with the stress experience may vary considerably by sex, and this may reflect one possible reason for the drug's relative efficacy in reducing 
stress- and cue-induced craving in women compared with men. Again, however, further systematic research is needed to more fully understand the sex specificity of not only the stress experience, but also the stress-induced craving state. Findings regarding these behaviors in men and women currently demonstrate much conflicting evidence due to paradigm variation and individual differences in subpopulations of drug users. Although some studies have shown stress-related craving to be associated with subjective emotion and behavioral arousal in healthy men but not women (Chaplin et al, 2008), other research has associated a more sensitized biophysiological state with elevated cocaine craving in dependent women compared with men (Fox et al, 2006). Elucidating these mechanisms will help clarify sex-specific targets and thus better-tailored treatments for cocaine use disorder.

Interpretation of sex specificity in the current study is limited to some extent by small sample number and lack of control for gender-sensitive factors relating to stress system function. These include childhood trauma and menstrual cycle phase, both of which are known to impact adrenergic (Pervanidou and Chrousos, 2007; Sinha et al, 2007a; Feltenstein et al, 2011) and HPA-axis function (Fox et al, 2008a; Carpenter et al, 2011). Inclusion of a non-stress and drug cue comparison imagery condition would also have provided a clearer understanding of the subtleties between biophysiological response to combined stress and cue compared with stress alone and cue alone. In addition, the possibility that other factors may have accounted for differences in craving, rather than gender per se, cannot be completely discounted. For example, sex differences in craving may have been influenced by the significant variation in amount of cocaine consumed before inpatient entry. This is irrespective of the fact that no differences in significance were observed when cocaine amount was used as a covariate in all baseline and response models. Another limitation also stems from the fact that the group and individual counseling provided during inpatient stay may have been more effective in males, contributing to the lower craving levels observed in male compared with female placebos. However, while this remains a possibility, greater variation between males and females on subjective reporting at baseline may have been expected if the inpatient environment had played a salient role. Moreover, while women are less likely than men to enter inpatient treatment, gender has not previously been documented as a significant predictor of treatment retention, completion or outcome (Sun, 2006; Greenfield et al, 2007). Future research that more thoroughly examines both consumption expectancies as well as previous nicotine consumption frequencies is also warranted in order to more fully assess the selectivity of guanfacine's effects on craving in males.

Despite these limitations, the current findings are the first to demonstrate that guanfacine may be a potentially efficacious medication for reducing physiological and emotional arousal mechanisms pertinent to the stress- and cue-induced craving state, especially in cocaine-dependent women who may also abuse alcohol and nicotine. This study indicates that women may be more vulnerable than men to withdrawal-related adrenergic adaptations as well as anxiety and mood related components of the craving state. As such, extended research is encouraged to more thoroughly delineate potential sex differences in the efficacy of alpha2 agonists, such as guanfacine, in individuals with cocaine use disorder.

\section{FUNDING AND DISCLOSURE}

This work was supported by The Connecticut Department of Mental Health and Addiction Services as well as the National Institute of Health (NIH) and the NIH Common Fund Grants R01-DA027130 (to Sinha), UL1-DE019586 (to Sinha), and PL1-DA024859 (to Sinha), 1K01-DA029040 (to Fox). Trial name of the grant: NCT00585754 http://clinicaltrials. gov/ct2/show/NCT00585754?term=\%28NCT00585754\%29

$\&$ rank $=1$. The authors declare no conflict of interest.

\section{ACKNOWLEDGEMENTS}

We would like to thank the staff at The Clinical Neuroscience Research Unit and The Substance Abuse Center located at The CMHC, as well as the staff at The Yale Stress Center for all their help in completing this study.

\section{REFERENCES}

Amato L, Minozzi S, Pani PP, Solimini R, Vecchi S, Zuccaro P et al (2011). Dopamine agonists for the treatment of cocaine dependence. Cochrane Database Syst Rev 12: CD003352.

Arnsten AF (2011). Prefrontal cortical network connections: key site of vulnerability in stress and schizophrenia. Int $J$ Dev Neurosci 29: 215-223.

Back SE, Brady KT, Jackson JL, Salstrom S, Zinzow H (2005). Gender differences in stress reactivity among cocaine-dependent individuals. Psychopharmacology 180: 169-176.

Baumann MH, Milchanowski AB, Rothman RB (2004). Evidence for alterations in alpha2-adrenergic receptor sensitivity in rats exposed to repeated cocaine administration. Neuroscience 125: 683-690.

Becker JB, Hu M (2008). Sex differences in drug abuse. Front Neuroendocrinol 29: 36-47.

Bergquist KL, Fox HC, Sinha R (2010). Self-reports of interoceptive responses during stress and drug cue-related experiences in cocaine- and alcohol-dependent individuals. Exp Clin Psychopharmacol 18: 229-237.

Biederman J, Melmed RD, Patel A, McBurnett K, Konow J, Lyne A et al (2008). A randomized, double-blind, placebo-controlled study of guanfacine extended release in children and adolescents with attention-deficit/hyperactivity disorder. Pediatrics 121: e73-e84.

Blanchard DC (1998). Stress-related psychopathology as a vulnerability factor in drug taking: The role of sex. In: Weatherington CLRoman AB (eds) Drug Addiction Research and the Health of Women. National Institute on Drug Abuse, NIH: Bethesda, USA, pp 151-164.

Brady KT, Back SE, Waldrop AE, McRae AL, Anton RF, Upadhyaya HP et al (2006). Cold pressor task reactivity: predictors of alcohol use among alcohol-dependent individuals with and without comorbid posttraumatic stress disorder. Alcohol, Clin Exp Res 30: 938-946.

Brady KT, McRae AL, Moran-Santa Maria MM, DeSantis SM, Simpson AN, Waldrop AE et al (2009). Response to corticotropin-releasing hormone infusion in cocaine-dependent individuals. Arch Gen Psychiatry 66: 422-430.

Brown ZJ, Tribe E, D'Souza NA, Erb S (2009). Interaction between noradrenaline and corticotrophin-releasing factor in the 
reinstatement of cocaine seeking in the rat. Psychopharmacology 203: 121-130.

Burke JH, Goldberger JJ, Ehlert FA, Kruse JT, Parker MA, Kadish AH (1996). Gender differences in heart rate before and after autonomic blockade: evidence against an intrinsic gender effect. Am J Med 100: 537-543.

Cahill L (2003). Sex-related influences on the neurobiology of emotionally influenced memory. Ann N Y Acad Sci 985: 163-173.

Carpenter LL, Shattuck TT, Tyrka AR, Geracioti TD, Price LH (2011). Effect of childhood physical abuse on cortisol stress response. Psychopharmacology 214: 367-375.

Carroll KM, Nich C, Ball SA, McCance E, Frankforter TL, Rounsaville BJ (2000). One-year follow-up of disulfiram and psychotherapy for cocaine-alcohol users: sustained effects of treatment. Addiction 95: 1335-1349.

Carroll KM, Rounsaville BJ, Bryant KJ (1993). Alcoholism in treatment-seeking cocaine abusers: clinical and prognostic significance. J Stud Alcohol 54: 199-208.

Cervo L, Rossi C, Samanin R (1993). Clonidine-induced place preference is mediated by alpha 2-adrenoceptors outside the locus coeruleus. Eur J Pharmacol 238: 201-207.

Chaplin TM, Hong K, Bergquist K, Sinha R (2008). Gender differences in response to emotional stress: an assessment across subjective, behavioral, and physiological domains and relations to alcohol craving. Alcohol Clin Exp Res 32: 1242-1250.

Degenhardt L, Chiu WT, Sampson N, Kessler RC, Anthony JC (2008). Toward a global view of alcohol, tobacco, cannabis, and cocaine use: findings from the WHO World Mental Health Surveys. PLoS Med 5: e141.

Eglen RM, Hudson AL, Kendall DA, Nutt DJ, Morgan NG, Wilson VG et al (1998). 'Seeing through a glass darkly': casting light on imidazoline 'I' sites. Trends Pharmacol Sci 19: 381-390.

Engberg G, Eriksson E (1991). Effects of alpha 2-adrenoceptor agonists on locus coeruleus firing rate and brain noradrenaline turnover in $\mathrm{N}$-ethoxycarbonyl-2-ethoxy-1,2-dihydroquinoline (EEDQ)-treated rats. Naunyn-Schmiedeberg's Arch Pharmacol 343: 472-477.

Erb S (2010). Evaluation of the relationship between anxiety during withdrawal and stress-induced reinstatement of cocaine seeking. Prog Neuropsychopharmacol Biol Psychiatry 34: 798-807.

Erb S, Hitchcott PK, Rajabi H, Mueller D, Shaham Y, Stewart J (2000). Alpha-2 adrenergic receptor agonists block stressinduced reinstatement of cocaine seeking. Neuropsychopharmacology 23: 138-150.

Erb S, Shaham Y, Stewart J (1998). The role of corticotropin-releasing factor and corticosterone in stress- and cocaine-induced relapse to cocaine seeking in rats. J Neurosci 18: 5529-5536.

Fattore L, Altea S, Fratta W (2008). Sex differences in drug addiction: a review of animal and human studies. Womens Health 4: 51-65.

Feltenstein MW, Henderson AR, See RE (2011). Enhancement of cue-induced reinstatement of cocaine-seeking in rats by yohimbine: sex differences and the role of the estrous cycle. Psychopharmacology 216: 53-62.

Feltenstein MW, See RE (2006). Potentiation of cue-induced reinstatement of cocaine-seeking in rats by the anxiogenic drug yohimbine. Behav Brain Res 174: 1-8.

First M, Spitzer RL, Gibbon M, Williams J (1995). Structured Clinical Interview for DSM-IV. Patient Edition American Psychiatric Press Inc: Washington DC, USA.

Fox HC, Garcia M Jr., Kemp K, Milivojevic V, Kreek MJ, Sinha R (2006). Gender differences in cardiovascular and corticoadrenal response to stress and drug cues in cocaine dependent individuals. Psychopharmacology 185: 348-357.

Fox HC, Hong KA, Paliwal P, Morgan PT, Sinha R (2008a). Altered levels of sex and stress steroid hormones assessed daily over a 28-day cycle in early abstinent cocaine-dependent females. Psychopharmacology 195: 527-536.
Fox HC, Hong KI, Siedlarz K, Sinha R (2008b). Enhanced sensitivity to stress and drug/alcohol craving in abstinent cocaine-dependent individuals compared to social drinkers. Neuropsychopharmacology 33: 796-805.

Fox HC, Hong KI, Siedlarz KM, Bergquist K, Anderson G, Kreek MJ et al (2009). Sex-specific dissociations in autonomic and HPA responses to stress and cues in alcoholdependent patients with cocaine abuse. Alcohol Alcohol 44: 575-585.

Fox HC, Seo D, Tuit K, Hansen J, Kimmerling A, Morgan PT et al (2012). Guanfacine effects on stress, drug craving and prefrontal activation in cocaine dependent individuals: preliminary findings. J Psychopharmacol 26: 958-972.

Fox HC, Sinha R (2009). Sex differences in drug-related stresssystem changes: implications for treatment in substance-abusing women. Harvard Rev Psychiatry 17: 103-119.

Fox HC, Sinha R (in press) The role of guanfacine as a therapeutic agent to address stress-related pathophysiology in cocaine dependent individuals. Adv Pharmacol.

Fox HC, Talih M, Malison R, Anderson GM, Kreek MJ, Sinha R (2005). Frequency of recent cocaine and alcohol use affects drug craving and associated responses to stress and drug-related cues. Psychoneuroendocrinology 30: 880-891.

Greenfield SF, Trucco EM, McHugh RK, Lincoln M, Gallop RJ (2007). The Women's Recovery Group Study: a Stage I trial of womenfocused group therapy for substance use disorders versus mixedgender group drug counseling. Drug Alcohol Depend 90: 39-47.

Heinsbroek RP, van Haaren F, Feenstra MG, van Galen H, Boer G, van de Poll NE (1990). Sex differences in the effects of inescapable footshock on central catecholaminergic and serotonergic activity. Pharmacol Biochem Behav 37: 539-550.

Heinsbroek RP, Van Haaren F, Van de Poll NE, Steenbergen HL (1991). Sex differences in the behavioral consequences of inescapable footshocks depend on time since shock. Physiol Behav 49: 1257-1263.

Izard C (1972). Patterns of Emotions: A New Analysis of Anxiety and Depression. Academic Press: New York, USA.

Kampman KM, Dackis C, Lynch KG, Pettinati H, Tirado C, Gariti P et al (2006). A double-blind, placebo-controlled trial of amantadine, propranolol, and their combination for the treatment of cocaine dependence in patients with severe cocaine withdrawal symptoms. Drug Alcohol Depend 85: 129-137.

Kudielka BM, Buske-Kirschbaum A, Hellhammer DH, Kirschbaum C (2004). Differential heart rate reactivity and recovery after psychosocial stress (TSST) in healthy children, younger adults, and elderly adults: the impact of age and gender. Int J Behav Med 11: $116-121$.

Mantsch JR, Vranjkovic O, Twining RC, Gasser PJ, McReynolds JR, Blacktop JM (2013). Neurobiological mechanisms that contribute to stress-related cocaine use. Neuropharmacology $76(\mathrm{Pt} \quad \mathrm{B})$ : 383-394.

Mantsch JR, Weyer A, Vranjkovic O, Beyer CE, Baker DA, Caretta H (2010). Involvement of noradrenergic neurotransmission in the stress- but not cocaine-induced reinstatement of extinguished cocaine-induced conditioned place preference in mice: role for beta-2 adrenergic receptors. Neuropsychopharmacology 35: 2165-2178.

McCance-Katz EF, Carroll KM, Rounsaville BJ (1999). Gender differences in treatment-seeking cocaine abusers-implications for treatment and prognosis. Am J Addict 8: 300-311.

McCance-Katz EF, Kosten TR, Jatlow P (1998). Concurrent use of cocaine and alcohol is more potent and potentially more toxic than use of either alone-a multiple-dose study. Biol Psychiatry 44: 250-259.

McDougle CJ, Black JE, Malison RT, Zimmermann RC, Kosten TR, Heninger GR et al (1994). Noradrenergic dysregulation during discontinuation of cocaine use in addicts. Arch Gen Psychiatry 51: 713-719. 
Nolen-Hoeksema S, Larson J, Grayson C (1999). Explaining the gender difference in depressive symptoms. J Pers Soc Psychol 77: 1061-1072.

Ostadal P, Ostadal B (2012). Women and the management of acute coronary syndrome. Can J Physiol Pharmacol 90: 1151-1159.

Patkar AA, Mannelli P, Peindl K, Murray HW, Meier B, Leone FT (2006). Changes in tobacco smoking following treatment for cocaine dependence. Am J Drug Alcohol Abuse 32: 135-148.

Pervanidou P, Chrousos GP (2007). Post-traumatic Stress Disorder in children and adolescents: from Sigmund Freud's 'trauma' to psychopathology and the (Dys)metabolic syndrome. Horm Metab Res 39: 413-419.

Saladin ME, Gray KM, Carpenter MJ, LaRowe SD, DeSantis SM, Upadhyaya HP (2012). Gender differences in craving and cue reactivity to smoking and negative affect/stress cues. Am J Addict 21: 210-220.

Sandberg K, Ji H (2012). Sex differences in primary hypertension. Biol Sex Differ 3: 7.

Scahill L, Barloon L, Farkas L (1999). Alpha-2 agonists in the treatment of attention deficit hyperactivity disorder. $J$ Child Adolesc Psychiatr Nurs 12: 168-173.

Scahill L, Chappell PB, Kim YS, Schultz RT, Katsovich L, Shepherd E et al (2001). A placebo-controlled study of guanfacine in the treatment of children with tic disorders and attention deficit hyperactivity disorder. Am J Psychiatry 158: 1067-1074.

Shaham Y, Erb S, Stewart J (2000). Stress-induced relapse to heroin and cocaine seeking in rats: a review. Brain Res Brain Res Rev 33: 13-33.

Shaham Y, Shalev U, Lu L, De Wit H, Stewart J (2003). The reinstatement model of drug relapse: history, methodology and major findings. Psychopharmacology 168: 3-20.

Shalev U, Grimm JW, Shaham Y (2002). Neurobiology of relapse to heroin and cocaine seeking: a review. Pharmacol Rev 54: 1-42.

Sica DA (2007). Centrally acting antihypertensive agents: an update. J Clin Hypertens 9: 399-405.

Siever LJ, Uhde TW (1984). New studies and perspectives on the noradrenergic receptor system in depression: effects of the alpha 2-adrenergic agonist clonidine. Biol Psychiatry 19: 131-156.

Sinha R (2009). Modeling stress and drug craving in the laboratory: implications for addiction treatment development. Addict Biol 14: 84-98.
Sinha R, Fox H, Hong KI, Sofuoglu M, Morgan PT, Bergquist KT (2007a). Sex steroid hormones, stress response, and drug craving in cocaine-dependent women: implications for relapse susceptibility. Exp Clin Psychopharmacol 15: 445-452.

Sinha R, Fox HC, Hong KA, Bergquist K, Bhagwagar Z, Siedlarz KM (2009). Enhanced negative emotion and alcohol craving, and altered physiological responses following stress and cue exposure in alcohol dependent individuals. Neuropsychopharmacology 34: 1198-1208.

Sinha R, Kimmerling A, Doebrick C, Kosten TR (2007b). Effects of lofexidine on stress-induced and cue-induced opioid craving and opioid abstinence rates: preliminary findings. Psychopharmacology 190: 569-574.

Sinha R, Shaham Y, Heilig M (2011). Translational and reverse translational research on the role of stress in drug craving and relapse. Psychopharmacology 218: 69-82.

Sinha R, Talih M, Malison R, Cooney N, Anderson GM, Kreek MJ (2003). Hypothalamic-pituitary-adrenal axis and sympathoadreno-medullary responses during stress-induced and drug cue-induced cocaine craving states. Psychopharmacology 170: $62-72$.

Smith RJ, Aston-Jones G (2008). Noradrenergic transmission in the extended amygdala: role in increased drug-seeking and relapse during protracted drug abstinence. Brain Struct Funct 213: 43-61.

Sofuoglu M (2010). Cognitive enhancement as a pharmacotherapy target for stimulant addiction. Addiction 105: 38-48.

Stout RL, Wirtz PW, Carbonari JP, Del Boca FK (1994). Ensuring balanced distribution of prognostic factors in treatment outcome research. J Stud Alcohol Suppl 12: 70-75.

Strang J, Bearn J, Gossop M (1999). Lofexidine for opiate detoxification: review of recent randomised and open controlled trials. Am J Addict 8: 337-348.

Sun AP (2006). Program factors related to women's substance abuse treatment retention and other outcomes: a review and critique. J Subst Abuse Treat 30: 1-20.

Uhlen S, Porter AC, Neubig RR (1994). The novel alpha-2 adrenergic radioligand [3H]-MK912 is alpha-2C selective among human alpha-2A, alpha-2B and alpha-2C adrenoceptors. J Pharmacol Exp Ther 271: 1558-1565.

Supplementary Information accompanies the paper on the Neuropsychopharmacology website (http://www.nature.com/npp) 